\title{
ESCRITAS FORA DO CORPO: A LITERATURA RESIDUAL DE ITALO CALVINO
}

\author{
Bruna Fontes Ferraz \\ Universidade Federal de Minas Gerais
}

\begin{abstract}
Resumo: O ensaio "La poubelle agréée", de Italo Calvino, publicado em O caminho de San Giovanni, apresenta uma temática inusitada se pensarmos a obra do escritor em questão: a escrita como lixo. Discorrendo sobre o ato de jogar o lixo para fora, Calvino estabelece considerações sobre a relação entre consumo e descarte, apropriação e expropriação, de modo que o destino dos bens consumidos seria a multiplicação dos resíduos expelidos. A proposta deste trabalho é, pois, refletir sobre a escrita como um desses resíduos expelidos pelo corpo, considerando que o que resta da escrita é também lixo, é também dejeto deposto do corpo do autor. Para reiterar essa relação entre escrita e excreção, nos basearemos em Nancy para quem a escrita se excreve, lança-se para fora e se inscreve no corpo do leitor. Temos, então, o homem como produtor de escórias e, consequentemente, a arte como escória. Baseando-nos, sobretudo, em Agamben, Benjamin e Didi-Huberman, discorreremos sobre a possibilidade de a literatura escatológica - dessacralizada, desauratizada - firmar-se como uma espécie de contradispositivo perante a sociedade de controle através da profanação.
\end{abstract}

Palavras-chave: Literatura residual. Escrita. Corpo. Italo Calvino.

[...] la spinta a scrivere è sempre legata alla mancanza di qualcosa che si vorrebbe conoscere e possedere, qualcosa che ci sfugge. Italo Calvino, "Mondo scritto e mondo non scritto".

[...] o impulso para escrever é sempre ligado à falta de alguma coisa que se gostaria de conhecer e possuir, alguma coisa que nos escapa.

O ato de levar o lixo para fora é tema do ensaio "La poubelle agréée", de Italo

\footnotetext{
* Licenciada em Língua Portuguesa pela Universidade Federal de Ouro Preto (2010), Mestre em Estudos Literários - Teoria da Literatura pela Universidade Federal de Minas Gerais (2013) e doutoranda do Programa de Pós-Graduação em Estudos Literários da UFMG. Atua principalmente com os seguintes temas: língua portuguesa, redação empresarial, teoria da literatura, possibilidades e potencialidades da narrativa na contemporaneidade, mímesis na modernidade, Italo Calvino. E-mail: brunafontesferraz@ymail.com.
} 
Calvino. ${ }^{1}$ Texto escrito na década de 1970 , a partir de reflexões do escritor quando de sua frequente atividade doméstica: a de retirar o lixo de casa, o lixo privado, e levá-lo para a lixeira da rua, transformando-o num lixo coletivo. A partir de um simples afazer doméstico, temos destrinchada toda uma concepção de mundo marcada pela estratificação étnica e pela opressão maniqueísta cristã-ocidental, que ao classificar os homens entre puros e pecadores determina toda uma carga semântica associada a tais conceitos. Se a pureza pressupõe o paraíso, a iluminação, a claridade, a limpeza; o pecado, por sua vez, se estende ao inferno, ao mal, ao obscuro, ao sujo, ao lixo.

Levar o lixo para fora faz parte, assim, conforme Calvino, de um agreement, um acordo, um contrato para que a cidade nos livre dos nossos resíduos de cada dia, das escórias produzidas pelo corpo. O homem teria, nesse sentido, necessidade de se ver livre desses resíduos, de afastar de si os destroços, as escórias, o lixo, relegando-os aos escombros da sociedade. Por isso, além de um contrato, esse mesmo ato de botar o lixo pra fora é também um rito: um rito de purificação, como se se livrar das escórias do corpo fosse a única forma de se encontrar novamente consigo mesmo. Ao se ver livre de seus dejetos, de suas sujeiras, o homem se tornaria novamente puro, limpo, isento de marcas:

rito de purificação, abandono das escórias de mim mesmo, não importando se se trata exatamente daquelas escórias contidas na poubelle ou se aquelas escórias remetem a qualquer outra possível escória minha; o que importa é que nesse meu gesto diário eu confirme a necessidade de me separar de uma parte do que era meu, os despojos ou a crisálida ou o limão espremido do viver, para que reste só a essência (CALVINO, 2000, p. 85).

Embora Calvino possa parecer, num primeiro momento, condescendente com esse rito de purificação - pela ideia de que ao se livrar dos resíduos produzidos pelo corpo ele próprio não seria dejeto, “despojo morto" (CALVINO, 2000, p. 86), perpetuando, desse modo, incessantemente, a vida -, acreditamos, como se pode constatar no decorrer do ensaio, que o escritor italiano faz uma crítica a essa tentativa de pureza, ${ }^{2}$ que oprime o ser vivente a um "ameaçador engenho" de purificação.

\footnotetext{
${ }^{1}$ Esse mesmo ensaio de Italo Calvino instiga também o notável artigo "Da coleção e do lixo: Calvino e o resíduo da escritura", de Claudia Maia (2013), texto que reflete sobre os conceitos de lixo e de coleção como metáfora da literatura.

${ }^{2}$ Para corroborar ainda mais a nossa leitura de que Calvino faria uma crítica a essa tentativa de buscar a essência, a interioridade, é importante salientarmos que o escritor italiano nunca se sentiu inclinado a escrever literatura psicológica, pois preferia o que se encontrava na superfície, na pele. Como um exemplo literal disso, citamos um trecho do ensaio "O museu dos monstros de cera", publicado em Coleção de areia, quando o escritor reflete sobre sua preferência pela pele ao invés das vísceras: "Estão expostos [no museu] não só modelos de cera, mas também objetos naturais, como uma pele humana completa, inteiramente montada, de um homem de 35 anos (peça única, adverte o catálogo, que nenhum museu do mundo possui): este tapete humano, esmagado como uma flor nas páginas de um livro, pareceu-me, ali onde estava, a imagem mais fraterna e repousante. Devo admitir
} 
O escritor observa que haveria uma espécie de vício estrutural da mente católicoitaliana (CALVINO, 2000, p. 87) que, justamente por ver a sujeira como símbolo do pecado, quisesse se separar de qualquer possível escória do corpo, o qual seria transformado num corpo sem marcas, sem história. O rito de purificação seria, portanto, um instrumento coercitivo que moldaria e controlaria o ser vivente, "limpando-o" de qualquer sinal que pudesse configurar sua própria experiência para, desse modo, reinscrever no seu corpo uma "História oficial".

Além disso, tudo o que de algum modo se relacionasse aos dejetos bem como à sua coleta seria considerado ínfimo, ignóbil, e os seres condenados a executar tais atividades, os éboueurs, ou seja, os removedores de lama, fariam parte de uma classe social cada vez mais marginalizada e relegada ao limbo social. O trabalho na cidade seria determinado a partir de estratificações étnicas, conforme observou Calvino ao direcionar seu olhar para a pálida Paris da década de 1970:

\begin{abstract}
Assim os éboueurs afloram das brumas da manhã, os traços não sobressaem do indeterminado: semblantes terrosos - os norte-africanos -, um pouco de bigode, um solidéu na cabeça; ou - os da África negra - só o bulbo dos olhos aclarando o rosto perdido na escuridão; vozes que se sobrepõem ao zumbido abafado do caminhão, sons desarticulados para nossos ouvidos, sons portadores de alívio ao se infiltrarem no sono da manhã, transmitindo a segurança de que se pode continuar a dormir mais um pouco pois outros estão trabalhando por você. A pirâmide social continua revolvendo suas estratificações étnicas: em Paris o trabalhador italiano já se transformou em pequeno empreendedor, o espanhol em operário qualificado, o iugoslavo em pedreiro, a mão-de-obra mais tosca é portuguesa, e, quando chegamos aos que removem a terra com a pá ou varrem as ruas, sempre é a mal descolonizada África a erguer seus olhos tristes da calçada da metrópole (CALVINO, 2000, p. 89).
\end{abstract}

Calvino compara, então, esse instrumento purificador ao incinerador, capaz de destruir, triturar, incinerar e transformar corpos em cinzas: "e você, no sono, sente que o caminhão não tritura apenas lixo, mas vidas humanas e papéis sociais e privilégios, e não para enquanto não tiver cumprido todo o seu percurso" (CALVINO, 2000, p. 89).

Vidas humanas como lixo, o lixo desprezado: esse é o mecanismo de controle de uma sociedade capitalista que se pauta no deus Capital, na relação de apropriação e expropriação, uma sociedade na qual aquele que joga fora confirma sua posse, signo de seu poder, enquanto aquele que recolhe o lixo extrai dali a noção da quantidade de bens dos quais é excluído. O destino do consumo é sempre o descarte, de modo que com a multiplicação dos

que jamais senti atração por vísceras (assim como nunca me senti fortemente inclinado a explorar a interioridade psicológica); daí talvez minha preferência por esse homem todo em extensão, desdobrado em toda a sua superfície, avesso a qualquer espessura e a qualquer intenção recôndita" (CALVINO, 2010, p. 35-36).

Anu. Lit., Florianópolis, v. 20, n. Esp 1, p. 93-103, 2015. ISSNe 2175-7917 
produtos fabricados há também a multiplicação dos resíduos expelidos. ${ }^{3}$ Por essa lógica, por essa rotatividade na qual tudo rapidamente se torna descartável, o que de fato chega ao homem são sempre restos inutilizáveis, a obra imprestável. Temos, então, uma reviravolta no ensaio calviniano, o qual passa a indicar que o resto, o lixo, mesmo desprezível, é a única coisa com a qual o ser humano precisa lidar, pois o que chega "para nosso uso e consumo [são] os restos mortais" (CALVINO, 2000, p. 92).

Há, pois, em "La poubelle agréée", uma tentativa de ressignificar o lugar desses dejetos, os quais - por mais que os homens queiram se ver livres deles - acabam sempre ressurgindo, impondo sua presença mesmo que pelo incômodo. O escritor italiano, assim, implicitamente, recupera Nietzsche ao afirmar que haveria um "eterno retorno do efêmero" (CALVINO, 2000, p. 100), ou seja, sempre os mesmos acontecimentos se repetindo indefinidamente e, com eles, as escórias, os dejetos, os resíduos a amedrontar os homens; por isso a necessidade de lidar com eles e não mais afastá-los.

Esse eterno retorno do efêmero assinala, portanto, uma possibilidade de salvação do lixo "para além do esfacelamento de toda produção e consumo" (CALVINO, 2000, p. 87), sendo que entre as sobras que mais interessam a Calvino está o resíduo da escrita, o resto que se salvou: "estes meus pensamentos que vocês leem são o que se salvou de dezenas de folhas amassadas no cesto" (CALVINO, 2000, p. 87). Entretanto, mais do que o resto salvo entre as inúmeras folhas amassadas e lançadas ao cesto durante a atividade do escritor, a escrita é ela própria lixo, na medida em que ela é expelida, expulsa do corpo: "Escrever é desapossar-se em grau não inferior a jogar fora, é afastar de mim um montão de folhas amassadas e uma pilha de folhas escritas até o fim, umas e outras já não minhas, depostas, expulsas" (CALVINO, 2000, p. 100).

As palavras são depostas, expulsas do corpo do escritor, tal como a secreção, a ejaculação, o excremento, por exemplo. Em seu ensaio sobre o lixo, Calvino menciona que o ato de lançar resíduos para fora geraria uma satisfação análoga à da defecação (CALVINO, 2000 , p. 86). Ora, se a própria escrita seria considerada dejeto deposto pelo corpo do autor, como não compararmos, nesse sentido, a escrita à defecação ${ }^{4}$ ? Baseando-nos em Freud,

\footnotetext{
${ }^{3}$ A relação entre o consumo e o descarte é tema, ainda em Calvino, de uma das cidades invisíveis. Leônia é sempre a cidade do lixo, que acumula camadas sobre camadas de dejetos na tentativa de renovar-se todos os dias: "O resultado é o seguinte: quanto mais Leônia expele, mais coisas acumula; as escamas do seu passado se solidificam numa couraça impossível de se tirar; renovando-se todos os dias, a cidade conserva-se integralmente em sua única forma definitiva: a do lixo de ontem que se junta ao lixo de anteontem e de todos os dias e anos e lustros" (CALVINO, 2003, p. 110).

${ }^{4}$ Esse tratamento escatológico da arte irrompe, sobretudo, com a vanguarda dadaísta de Duchamp e o seu urinol. Mas lembremo-nos, ainda, de Piero Manzoni, que, por vias muito mais extremas, modificou toda uma concepção
} 
poderíamos pensar que o dejeto da escrita estivesse associado à relação que a criança mantém com suas fezes. Conforme considera Freud, "o excremento é o primeiro presente, a primeira oferenda de ternura da criança, uma parte do próprio corpo de que ela se despoja, mas apenas para alguém que ama" (FREUD, 2010, p. 72). A escrita seria, pois, a renúncia a um pedaço do corpo que é desprendido, lançado e ejetado.

"Um jacto e não um subjectum” (NANCY, 2000, p. 14). Nancy, em seu livro Corpus, retira todo o "sub" presente na escrita, não se orientando mais pelo "ego", pelo que se encontra na interioridade, na essência do ser, ao propor uma escrita sem autos, uma escrita do corpo, do limite, da borda, da exterioridade. Por isso um jacto de escrita, lugar do corpo aberto e da ausência de sentido:

Um sentido que faz sentido no lugar em que, para o sentido, existe um limite. Sentido mudo, fechado, autista: mas sem autos, justamente, sem "si próprio". O autismo sem autos do corpo, o que faz dele muitíssimo menos do que um "sujeito", mas também algo de extremamente diverso, um jacto e não um subjectum, que é tão duro, tão intenso e inevitável, tão singular como um sujeito (NANCY, 2000, p. 14).

É necessário retomarmos ainda que jacto vem do latim jacio e que, entre suas acepções, além de "lançar, arremessar, atirar, desferir, exalar (um cheiro)", temos também a noção de "proferir, dizer, lançar a ideia" (FERREIRA, 2001, p. 376). O corpo como jacto é, desse modo, aquilo que foi arremessado para fora, para esse lugar aberto, através do corpus, ou seja, do texto: "é assim que a ontologia se revela como escrita" (NANCY, 2000, p. 18). Nessa perspectiva, a escrita abre-se para fora, lança-se para a exterioridade, num movimento similar ao do excremento sendo lançado para fora do corpo. A teoria de Nancy reitera o próprio lugar da escrita como forma de excreção, por isso o teórico francês utiliza a denominação "excrita", isso que seria o corpus do texto, esvaziado de todo significado ao deixar a palavra à deriva; isso que seria escrever o corpo, "tocar o corpo com o incorpóreo do sentido" (NANCY, 2000, p. 11):

A excrição do nosso corpo, eis por onde se deve passar, antes de tudo. A sua inscrição-fora, a sua deslocação fora-de-texto como o movimento mais próprio do seu texto: o texto mesmo abandonado, deixado no seu limite. Já não se trata de uma "queda", já não há alto nem baixo, o corpo não é rebaixado: todo ele está no limite, no bordo externo, extremo, sem que nada o possa de novo fechar. Eu diria que o anel das circuncisões se rompeu, e que resta agora uma linha in-finita, o traço da própria escrita excrita, num rasto infindavelmente quebrado, partilhado através da multidão dos corpos (NANCY, 2000, p. 12-13).

tradicional de arte com a sua exposição "Merde d'artista" ("Merdas de artista"). Ao produzir 90 latinhas supostamente preenchidas com suas fezes, o artista italiano manifestou uma crítica à sociedade de consumo, embora, ironicamente, suas latinhas tenham sido vendidas a preços exorbitantes. 
$\mathrm{O}$ corpo vem à tona, pois, dando visibilidade a todas as suas deformidades ou às escórias que, antes, deveriam ser escondidas, "varridas para debaixo do tapete”. Já não há alto, nem baixo, céu ou inferno, somente esse corpo excrito que pelo toque estabelecido pelas palavras viabiliza um ponto de encontro, de intersecção, de contato. Um contato, talvez, entre aquele que descarta e aquele que recolhe o lixo, sendo esse contato a única comunicação possível entre consumidores e lixeiros, como dizia Calvino. Ou, então, entre autor e leitor, que estabelecem uma relação pela palavra. A palavra teria, portanto, a mesma função do lixo, ambos fariam essa mediação, essa comunicação.

A palavra toca nos corpos, não no sentido físico do toque, mas, conforme considera Nancy, por "um tacto que é como o gesto de endereçar" (NANCY, 2000, p. 18). A palavra, pelo endereçamento, permite que autor e leitor se toquem, mas esse contato - "retirado, espaçado, apartado" (NANCY, 2000, p. 19) - é sempre estranho. O tato proposto pelo filósofo francês perpassa, pois, o tocar o corpo das palavras, já que "há corpos que se tocam sobre esta página, ou melhor, ela própria é o contacto (da minha mão que escreve, das tuas que seguram o livro)" (NANCY, 2000, p. 51). Um contato pela superfície do texto; não há mais, portanto, nenhuma perspectiva de decifrar, de encontrar o sentido oculto, pois, desde Deleuze, “o interior e o exterior, o profundo e o alto, não têm valor biológico a não ser por esta superfície topológica de contacto. É, pois, até mesmo biologicamente que é preciso compreender que 'o mais profundo é a pele"” (DELEUZE, 2007, p. 106).

É nesse sentido que o corpus ocupa um espaço, uma superfície, uma área. Para Nancy, o termo "arealidade" determina tanto o caráter espacial desse contato quanto o seu desvencilhamento da realidade, pois esse corpus está sempre no âmbito do corpo do texto, da escrita, da palavra, enfim. Por isso,

este tocar é infinitamente desviado, diferido (...), mas resta o ínfimo grão obstinado, ténue, a poeira infinitesimal de um contacto que por toda a parte se interrompe e por toda a parte se retoma. E no final, o teu olhar toca nos mesmos traçados de caracteres em que o meu toca agora, e tu lês-me, e eu escrevo-te. Algures, o contacto tem lugar (NANCY, 2000, p. 51).

A excrição, a excrita, produz-se quando desse contato entre autor e leitor, o contato pela página: a escrita se excreve, lança-se para fora e se inscreve no corpo do leitor. Quando expelida, removida da pele autoral, mas sempre nela mantendo suas cicatrizes, essa excrita se torna alimento para o leitor. Calvino já observava esse movimento de desapossar-se da escrita em prol daquele que lê, observando o caráter residual que há na palavra, lixo do autor, que será reciclado pelo leitor, num movimento cíclico de retorno do efêmero, pois a leitura 
ingerida alimenta, tornando-se novamente texto, e tudo aquilo que alimenta também deve ser expelido. Nas palavras de Calvino:

a escrita, que, uma vez terminada, já não faz parte de mim e que ainda não podemos saber se vai se tornar alimento de uma leitura alheia, de um metabolismo mental, quais transformações sofrerá passando através de outros pensamentos, quanto transmitirá de suas calorias, e se tornará a colocá-las em circulação (CALVINO, 2000, p. 100).

Temos, então, o homem como produtor de escórias e, consequentemente, a arte como escória. Com esse movimento, já não há mais distinção entre puro e impuro, ou melhor, tudo estaria relacionado ao abjeto, dessacralizando-se, desse modo, a obra de arte. E, justamente por não serem mais sagradas, a arte e a escrita são deslocadas para um lugar outro, esvaziadas de qualquer significado, fazendo frente a um domínio opressor que, geralmente, se inscreve pelo idioma. Quando usada como expressão obrigatória do poder, a escrita, ou, mais precisamente, a linguagem seria um dispositivo de controle empregado para concretizar as relações de poder, "cujo objetivo é gerir, governar, controlar e orientar, num sentido que se supõe útil, os gestos e os pensamentos dos homens" (AGAMBEN, 2009, p. 39). Ora, se a linguagem talvez seja o mais antigo dos dispositivos de controle, como seria possível usá-la sem estabelecer uma relação de poder? Sem assujeitar o leitor ao saber imposto pelo autor? Como poderíamos fazer frente a esse dispositivo?

Para Didi-Huberman, isso só seria possível através de um "não-saber", ou seja, um saber clandestino, intermitente, obscuro: um saber-vaga-lume com o seu simples lampejo na noite, que protestaria contra e sobreviveria a qualquer tentativa de controle e assujeitamento dos seres viventes. Ou, então, conforme considera Agamben, a melhor maneira de resistirmos aos dispositivos seria através da profanação. Mas se a linguagem é coercitiva quando usada pelo poder soberano, como essa mesma linguagem poderia ser vaga-lume ou profana?

É justamente essa escrita lixo, expelida, defecada, excrita, portanto, que sobrevive, que profana, fazendo frente aos dispositivos de controle. Agamben, citando o grande jurista Trebazio, conceitua profano como aquilo "que, de sagrado ou religioso que era, é restituído ao uso e à propriedade dos homens" (AGAMBEN, 2009, p. 45). Se para ser profano é necessário ter saído da esfera do sagrado, como a linguagem - essencialmente humana - poderia ser profana?

Ora, basta lembrarmo-nos das citações bíblicas para evidenciarmos o caráter sagrado com o qual por muito tempo foi investida a linguagem: "no princípio era o verbo" e "o verbo se fez carne" revelam a natureza religiosa conferida à palavra, como escritura, como a própria voz de Deus. Entretanto, mesmo continuando no âmbito bíblico, vemos que o próprio caráter 
sacro da linguagem é profanado e, assim, restituído ao uso humano, por meio da eucaristia. O verbo que se fez carne, ou seja, o Cristo que dá o seu corpo e o seu sangue para ser devorado pelos apóstolos. Comer o deus, comer o sagrado, transformá-lo em parte do seu corpo e defecá-lo, haveria gesto de profanação maior? É nesse sentido que Didi-Huberman, em seu ensaio "Disparates sobre a voracidade", compara a eucaristia a uma relação erótica e, por isso, novamente, um ato profano: "frases abissais - sexualmente abissais. Frases de amor místico, isto é, portadoras de uma voracidade total: ama a mim, vem a mim, fica em mim - come a mim. E tu gozarás eternamente" (DIDI-HUBERMAN, 1998, p. 193).

A escrita do corpo, corpus, como quer Nancy, é, talvez, esse contradispositivo que, ao profanar, permite ao ser vivente se desvencilhar, mesmo que por um átimo, do controle biopolítico. A profanação não restaura o sagrado ao humano sem nenhuma contaminação, o corpo do Cristo ao ser profanado não voltará a ser carne, pão; há uma libertação da função utilitária ao investir o corpo profanado a um novo uso: "O comportamento libertado dessa forma reproduz e ainda expressa gestualmente as formas da atividade de que se emancipou, esvaziando-as, porém, de seu sentido e da relação imposta com uma finalidade, abrindo-as e dispondo-as para um novo uso" (AGAMBEN, 2007, p. 74). O verbo da voracidade, da carne, do corpo, do excremento é a linguagem que se emancipa de seus fins comunicativos e sagrados, e se prepara para um novo uso; daí o conceito de profano para Agamben.

Para refletir sobre o conceito da profanação, o filósofo italiano parte da própria noção de sagrado, que pressupõe uma separação de tudo o que estaria na esfera humana. Para atingir o sagrado seria necessário, então, um esforço, um sacrifício que estabelecesse a passagem de algo profano para o sagrado. Sendo esse movimento possível, o inverso também o seria:

\begin{abstract}
O que foi separado ritualmente pode ser restituído, mediante o rito, à esfera profana. Uma das formas mais simples de profanação ocorre através de contato (contagione) no mesmo sacrifício que realiza e regula a passagem da vítima da esfera humana para a divina. Uma parte dela (as entranhas, exta: o fígado, o coração, a vesícula biliar, os pulmões) está reservada aos deuses, enquanto o restante pode ser consumido pelos homens. Basta que os participantes do rito toquem essas carnes para que se tornem profanas e possam ser simplesmente comidas. Há um contágio profano, um tocar que desencanta e devolve ao uso aquilo que o sagrado havia separado e petrificado (AGAMBEN, 2007, p. 66).
\end{abstract}

O contato profana, portanto, o objeto que poderia se tornar sagrado. Basta que o homem, com suas mãos pecaminosas (e, novamente, temos a metáfora da sujeira, do pecado, da impureza separando o humano do sagrado), toque o corpo sagrado para que este seja profanado. O mesmo contato previsto por Nancy que aproximaria leitor e autor pelos 
caracteres da página, pela mão que escreve e pelo olho que lê, esse contato que torna a escrita excrita, profanada, por sua vez. Toque que pressupõe mais do que a simples carícia, pressupõe, também, o rito antropofágico, devorar e comer o que seria sagrado, o rito eucarístico ainda:

\begin{abstract}
A doutrina da encarnação garantia que a natureza divina e a humana estivessem presentes sem ambiguidade na mesma pessoa, assim como a transubstanciação garantia que as espécies do pão e do vinho se transformassem, sem resíduos, no corpo de Cristo. Acontece assim que, no cristianismo, com a entrada de Deus como vítima do sacrifício e com a forte presença de tendências messiânicas que colocaram em crise a distinção entre o sagrado e o profano, a máquina religiosa parece alcançar um ponto limítrofe ou uma zona de indecidibilidade, em que a esfera divina está sempre prestes a colapsar na esfera humana, e o homem já transpassa sempre para o divino (AGAMBEN, 2007, p. 70).
\end{abstract}

É esse uso incongruente do sagrado que permite a profanação, não só pela restituição do sacro ao uso humano, mas por reinvesti-lo de um novo uso, num jogo, portanto. As partes do corpo que seriam sacrificadas e tornadas, por sua vez, sagradas, não voltaram ao funcionamento biológico, mas se tornaram alimento para, em seguida, serem digeridas e defecadas.

O corpus ${ }^{5}$ como alimento foi também tema do conto calviniano "Sob o sol jaguar", presente em livro homônimo. Nesse conto, o sabor, a experiência gustativa, guia os dois protagonistas, um casal de turistas italianos, a devorar a comida local pelo desejo de saber e conhecer a cultura do México. O prazer gastronômico acaba se entrelaçando com a temática dos ritos antropofágicos, quando o narrador, o marido, percebe a aparência canibalesca da esposa:

Era a sensação de seus dentes em minha carne que estava imaginando, e sentia a sua língua erguer-me contra a abóboda palatal, envolver-me em saliva, depois empurrarme sob a ponta dos caninos. Estava sentado ali na frente dela mas ao mesmo tempo me parecia que uma parte de mim ou eu inteiro estivesse contido em sua boca, triturado, dilacerado fibra por fibra (CALVINO, 1995, p. 51).

Essa voracidade canibalesca que envolvia a esposa também direcionava os desejos do marido, embora para ele o fascínio e a fome estivessem no nome da comida: "Era o nome [...] que eu apreciava sobretudo e assimilava e possuía. Tanto que a magia do nome continuou a atuar sobre mim mesmo depois da refeição" (CALVINO, 1995, p. 54-55). O ritual antropofágico, mais do que uma relação entre corpos ou entre o corpo e a comida, era também um alimentar-se dos nomes, da palavra: deglutir, saborear a palavra, a própria escrita.

\footnotetext{
${ }^{5}$ Ressaltamos que quando usamos a acepção corpus estamos sempre retomando o sentido desenvolvido por Jean-Luc Nancy, para quem corpus se refere ao texto, à escrita.
} 
Um "processo de ingestão e digestão" (CALVINO, 1995, p. 56). Essa é a metáfora da literatura de Calvino que se apresentou para nós desde "La poubelle agréée". A palavra que alimenta, que é ingerida, devorada, deglutida, dilacerada para depois ser digerida, defecada, eliminada. A palavra expulsa do corpo como as fezes, esse é o novo uso da linguagem empreendido pelo escritor d'As cidades invisiveis, profanando a escrita sagrada e, assim, desativando os dispositivos de poder.

A escrita, o lixo e a excreção compartilham, portanto, o mesmo lugar recluso, indesejável, alheio aos homens; são sempre sobras, resíduos, fragmentos, ou seja, pedaços de corpus eliminados, tal como as ideias soltas, residuais, como se jogadas no cesto de lixo, que Calvino concebe no final de seu ensaio "La poubelle agréée":

\begin{abstract}
tema da purificação das escórias/ o jogar fora é complementar da apropriação/ inferno de um mundo em que nada fosse jogado fora/ somos o que não jogamos fora/ identificação de nós mesmos/ lixo como autobiografia/ satisfação do consumo/ defecação/ tema da materialidade, do refazer, mundo agrícola/ a cozinha e a escrita/ autobiografia como lixo/ transmitir para conservar. [...] tema da memória/ expulsão da memória/ memória perdida/ guardar e perder o que está perdido/ o que não se teve/ o que se teve demasiado tarde/ o que carregamos conosco/ o que não nos pertence/ viver sem carregar nada junto (animal): carregamos conosco talvez mais/ viver para a obra; nos perdemos; há a obra imprestável, não há mais eu (CALVINO, 2000, p. 100-101).
\end{abstract}

Com expressões residuais, com lixos, Calvino finaliza o seu ensaio, e, com ele, também nós. As ideias que o escritor enumerou durante anos para escrever "La poubelle agréée" são restos que não necessariamente foram todos reciclados em seu texto, mas o mesmo texto finaliza em pó, ao desmoronar-se em palavras soltas que anunciam o fim do "eu”. "Há a obra imprestável, não há mais eu", conclui Calvino, abrindo espaço, desse modo, para uma nossa última suposição: há a palavra, há a palavra excrita.

\title{
Agradecimentos
}

À Simone Garcia de Oliveira, pela tradução cuidadosa do resumo deste artigo para a língua inglesa.

\section{Referências}

AGAMBEN, Giorgio. Elogio da profanação. In: AGAMBEN, Giorgio. Profanações. Trad. de Selvino José Assman. São Paulo: Boitempo, 2007.

AGAMBEN, Giorgio. O que é o contemporâneo? e outros ensaios. Trad. de Vinícius Nicastro Honesko. Chapecó: Argos, 2009.

CALVINO, Italo. Sob o sol-jaguar. Trad. de Nilson Moulin. São Paulo: Companhia das Letras, 1995. 
CALVINO, Italo. La poubelle agréée. In: CALVINO, Italo. O caminho de San Giovanni. Trad. de Roberta Barni. São Paulo: Companhia das Letras, 2000.

CALVINO, Italo. As cidades invisíveis. Trad. de Diogo Mainardi. São Paulo: Folha de S. Paulo, 2003.

CALVINO, Italo. O museu dos monstros de cera. In: CALVINO, Italo. Coleção de areia. Trad. de Maurício Santana Dias. São Paulo: Companhia das Letras, 2010.

DELEUZE, Gilles. Lógica do sentido. Trad. de Luiz Roberto Salinas Fortes. São Paulo: Perspectiva, 2007.

DIDI-HUBERMAN, Georges. Disparates sobre a voracidade. In: XXIV Bienal de São Paulo: Roteiros. São Paulo, Fundação Bienal, 1998, p. 190-196.

FERREIRA, Antonio Gomes. Dicionário de latim português. Porto: Porto Editora, 2001.

FREUD, Erotismo anal e complexo da castração. In: Obras Completas de Sigmund Freud Volume 14. Trad. e notas de Paulo César de Souza. São Paulo: Companhia das Letras, 2010.

MAIA, Claudia. Da coleção e do lixo: Calvino e o resíduo da escritura. In: KLEIN, Adriana Iozzi; MOREIRA, Maria Elisa Rodrigues (Orgs.). Escrever também é outra coisa: ensaios sobre Italo Calvino. São Paulo: Nova Alexandria, 2013. p. 125-137.

NANCY, Jean-Luc. Corpus. Trad. de Tomás Maia. Lisboa: Vega, 2000.

\section{Out-of-body writings: Italo Calvino's residual literature}

Abstract: The essay "La poubelle agréée" by Italo Calvino, published in The Road to San Giovanni, features an unusual theme when we consider the writer's work in question: writing as garbage. Discussing the act of taking out the garbage, Calvino established some considerations on the relationship between consumption and disposal, appropriation and expropriation, so that the destination of consumed goods would be a multiplication of the expelled residues. Therefore, this paper aims at reflecting on writings as one of the residues that are excreted by the body, considering that what remains from writings are also garbage, a waste deposed from the author's body. To reiterate this relationship between writing and excretion, we rely upon Corpus by Jean Luc Nancy, for whom the writing throws itself away from the author's body, inscribing itself in the reader's body. We thus understand man as a scum producer, and consequently the arts as scum as well. Based mainly on Agamben, Benjamin and Didi-Huberman, we discuss the possibility of the eschatological literature desecrated, de-auralized - establishing itself as a kind of counter-apparatus before the controlling society through profanity.

Keywords: Residual literature. Out-of-body writings. Italo Calvino.

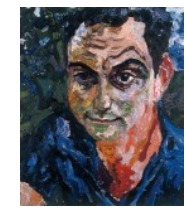

